Short Communication

\title{
Electrochemical Study of the Oxygen Evolution Reaction on MoNi/Carbon Fibre Electrode in 0.1 M NaOH
}

\author{
Tomasz Mikolajczyk ${ }^{1, *}$, Andrii Slis ${ }^{2}$, Tetyana Solodovnik ${ }^{2}$ \\ ${ }^{1}$ Department of Chemistry, Faculty of Environmental Management and Agriculture, University of \\ Warmia and Mazury in Olsztyn, Plac Lodzki 4, 10-957 Olsztyn, Poland \\ ${ }^{2}$ Department of Chemical Technology and Water Treatment, Faculty of Construction, Cherkasy State \\ Technological University, Shevchenko Boulevard, 460, 18006 Cherkasy, Ukraine \\ *E-mail: tomasz.mikolajczyk@uwm.edu.pl
}

doi: $10.20964 / 2019.02 .59$

Received: 3 October 2018 / Accepted: 20 November 2018 / Published: 5 January 2019

The oxygen evolution reaction (OER) was investigated on pure carbon fibre $\mathrm{CF}$ and $\mathrm{MoNi} / \mathrm{CF}$ tow electrodes in $0.1 \mathrm{M} \mathrm{NaOH}$ electrolyte at room temperature. MoNi alloy modification of $\mathrm{CF}$ was carriedout by electrodeposition in an electrolytic bath. The OER activity of both catalyst materials was examined by means of a.c. impedance spectroscopy and Tafel polarization techniques. The deposition of MoNi alloy on the CF material was evidenced by energy dispersive X-ray (EDX) spectroscopy; additionally, its presence had a significant influence on the recorded electrochemical parameters, such as charge-transfer resistance and exchange-current density.

Keywords: Carbon fibre; CF; MoNi alloy; impedance spectroscopy; OER

\section{FULL TEXT}

(C) 2019 The Authors. Published by ESG (www.electrochemsci.org). This article is an open access article distributed under the terms and conditions of the Creative Commons Attribution license (http://creativecommons.org/licenses/by/4.0/). 